\section{Detection of stratospheric nitrogen species}

SIR-When Toon et al.' claimed a definitive detection of $\mathrm{N}_{2} \mathrm{O}_{5}$ in the stratosphere from atmospheric trace molecule spectroscopy (ATMOS) data, they showed only one absorption band that could be attributed to $\mathrm{N}_{2} \mathrm{O}_{5}$. They claimed another band near $1,700 \mathrm{~cm}^{-i}$ was evident, but this claim might be thought dubious because there are strong overlapping bands of $\mathrm{HNO}_{3}$ at $1,700 \mathrm{~cm}^{-1}$, which differ between Northern Hemisphere (sunset) and Southern Hemisphere (sunrise) spectra, and the authors did not show this other band. My own tentative measurement of $\mathrm{N}_{2} \mathrm{O}_{5}$ (ref. 2) has been described by Camy-Peyret and others as a measurement of "an $\mathrm{N}_{2} \mathrm{O}_{5}$-like substance." So far, the ATMOS detection could rightly be claimed to be one of "an even more $\mathrm{N}_{2} \mathrm{O}_{5}$ like substance", but it is not an unambiguous detection as the authors claim. The evidence for it being $\mathrm{N}_{2} \mathrm{O}_{5}$ is very good, but many constituents have $\mathrm{P}_{-}$and R-branch features like the observed absorption, and although none is known at the observed wavelength, chemists are not infallible at predicting which trace constituents will or will not exist.

Most spectroscopists would agree that a definitive identification can only be claimed when two isolated or wellresolved lines or bands are observed simultaneously. This point was clearly stated by Rinsland et al. ${ }^{3}$, who analysed balloon-borne spectra to search for absorption by $\mathrm{ClONO}_{2}$ - they declined to claim a detection of $\mathrm{ClONO}_{2}$ because they observed two bands, but on different balloon flights. This was left for the ATMOS team ${ }^{4}$ who analysed four bands of $\mathrm{ClONO}_{2}$ has clearly taken the point because its tentative detection of $\mathrm{HO}_{2} \mathrm{NO}_{2}$ (ref. 5), which consisted of one band only, was entitled "Evidence for the presence of ..."

Over a year has elapsed, and Toon et al. have still not published additional spectra to establish their claim. Yet they continue to assert that they have definitively measured $\mathrm{N}_{2} \mathrm{O}_{5}$, most recently in a paper submitted to the Journal of Geophysical Research $^{6}$. Furthermore, administrators and published two. The ATMOS team

have accepted their assertions: in their 1986 report to the United Nations Environment Programme (UNEP), the Coordinating Committee on the Ozone Layer claimed that "the presence of the temporary reservoir species $\mathrm{ClONO}_{2}$, $\mathrm{N}_{2} \mathrm{O}_{5}$ and $\mathrm{HO}_{2} \mathrm{NO}_{2}$ in the stratosphere has been definitively established by recent observations". This is false on two counts.

I am as keen as anyone to establish that the broad absorption band observed in the atmosphere at $1,240 \mathrm{~cm}^{-1}$ arises from $\mathrm{N}_{2} \mathrm{O}_{5}$ because I can then continue to measure it with my radiometer and label the measurements ' $\mathrm{N}_{2} \mathrm{O}_{5}$ ' without the '-like substance'. But the authors do us all a disservice by claiming a positive identification without the proper evidence.

H.K. Roscoe

Department of Atmospheric Physics,

Clarendon Laboratory,

Parks Road, Oxford OXI 3PU, UK

1. Toon, G.C., Farmer, C.B. \& Norton, R.H. Nature 319 570-571 (1986).

. Roscoe, H.K. Geophys. Res. Lett. 9, 901 (1982)

3. Rinsland, C.P. et al. J. geophys. Res. 90, 7931-7943 (1985).

4. Zander, R., Rinsland, C.P., Farmer, C.B., Brown, L.R.\& Norton, R.H. Geophys. Res. Lett. 13, 757-760 (1986).

Rinsland, C.P. et al. Geophys. Res. Lett. 13, 761-764 (1986)

6. Russell, J.M. III et al. J. geophys. Res. (submitted).

Toon replies-When we submitted our paper $^{1}$ we felt that an additional figure showing the $1,725 \mathrm{~cm}^{-1}$ band of $\mathrm{N}_{2} \mathrm{O}_{5}$ would add little to the paper because of its similarity to the existing figure of the 1,250 $\mathrm{cm}^{-1}$ band and because the identification was less clear-cut. I agree with Dr Roscoe that there are strong $\mathrm{HNO}_{3}$ absorptions in the same spectral region as the $1,725 \mathrm{~cm}^{-1}$ $\mathrm{N}_{2} \mathrm{O}_{5}$ band, but the fact that the $\mathrm{N}_{2} \mathrm{O}_{5}$ layer peaks at a higher altitude than that of $\mathrm{HNO}_{3}$ allows the $\mathrm{N}_{2} \mathrm{O}_{5}$ band to be observed without excessive interference over a narrow range of tangent heights $(30-35 \mathrm{~km})$. Figure 1 shows four spectra taken in this tangent-height range, two at sunrise and two at sunset. Because $\mathrm{N}_{2} \mathrm{O}_{5}$ is almost completely photolysed during the daytime, the sunrise spectra should contain its spectral signature and the sunset spectra should not. Figure 2 shows, superimposed upon the $30.6-\mathrm{km}$ sunrise spectrum, separate calculations of the spectral signatures of $\mathrm{N}_{2} \mathrm{O}_{5}, \mathrm{HNO}_{3}$ and $\mathrm{O}_{3}$ in the same observation geometry. All of these features can be identified in the spectrum; the additional strong, randomly posi-

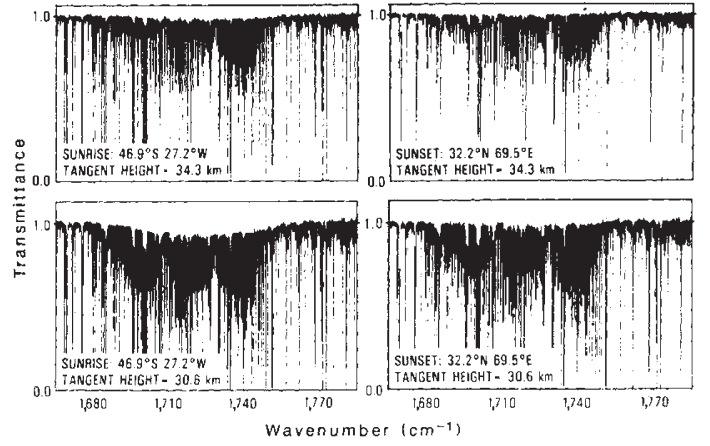

Fig. 1 Four infrared atmospheric transmittance spectra measured by the ATMOS sensor from $262-\mathrm{km}$ altitude on 30 April 1985 (sunset) and 1 May 1985 (sunrise).

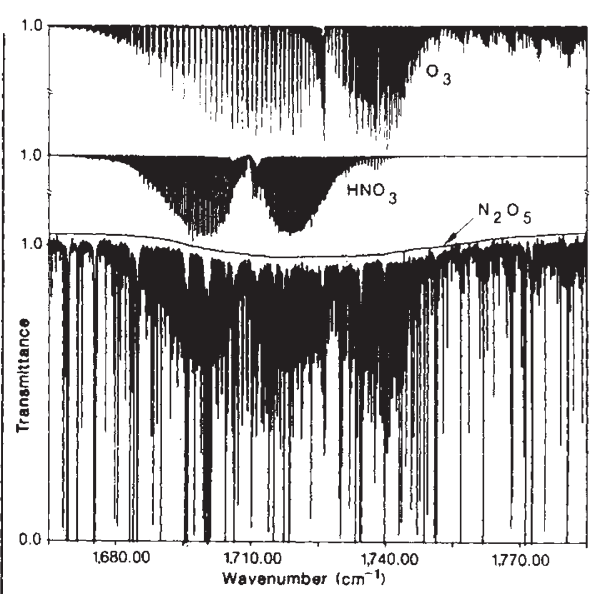

Fig. 2 A superposition of the 30.6-km sunrise spectrum of Fig. 1 and calculated spectra of $\mathrm{N}_{2} \mathrm{O}_{5}, \mathrm{HNO}_{3}$ and $\mathrm{O}_{3}$ offset for clarity. Absorption of all three molecules can be identified in the sunrise spectrum beneath the confusion of strong water-vapour lines.

tioned spectral lines result from water vapour. Although the sunrise-sunset difference of the measured spectra does not conform exactly to the $\mathrm{N}_{2} \mathrm{O}_{5}$ signature, the wings of the latter being too large, only the most sceptical critic could fail to attribute this difference to $\mathrm{N}_{2} \mathrm{O}_{5}$. The calculated spectrum of the $1,725 \mathrm{~cm}^{-1} \mathrm{~N}_{2} \mathrm{O}_{5}$ band was based on the room temperature laboratory measurements of Murcray et al. ${ }^{2}$, with all spectral lines assumed to have the same ground state energy. Had we given these spectral lines a more realistic temperature dependence, by increasing their ground state energies away from the centre of the band (as Toon et al. ${ }^{1}$ did for the $1,250 \mathrm{~cm}^{-1}$ band) the calculated wings of the 1,725 $\mathrm{cm}^{-1}$ band would have been weaker at stratospheric temperatures and ther agreement with the measurement perhaps even better. This emphasizes the need for accurate low-temperature, laboratory measurements of both of these $\mathrm{N}_{2} \mathrm{O}_{5}$ bands so that the untapped information about $\mathrm{N}_{2} \mathrm{O}_{5}$ contained in the ATMOS spectra can be accurately reduced to volumemixing-ratio profiles.

\section{Jet Propulsion Laboratory,}

$$
\text { G. Toon }
$$

California Institute of Technology,

4800 Oak Grove Drive,

Pasadena, California 91109, USA

1. Toon, G.C., Farmer, C.B. \& Norton, R.H. Nature 319, 570-571 (1986)

2. Murcray, D.J., Murcray, F.J., Goldman, A., Bonano, F.S. \& Blatherwick, R.D. High Resolution Infrared Laboratory Spectra (Dept. Physics, Univ. Denver, 1984).

\section{Incubation period for AIDS}

SrR-Comments on my article, "The sombre view of AIDS"1 have been uniformly critical. I would include in this a recent article by Medley et $a l^{2}$ on the AIDS (acquired immune deficiency syndrome) incubation period. Nearly all the criticisms focus on the estimation of the 